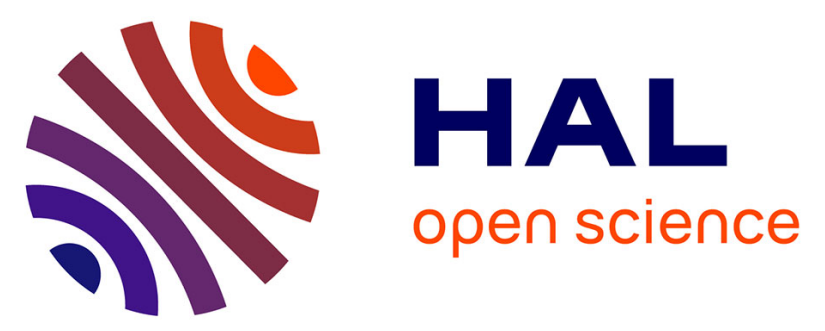

\title{
Monolithic integration of ultraviolet microdisk lasers into photonic circuits in a III-nitride-on-silicon platform
}

Farsane Tabataba-Vakili, Blandine Alloing, Benjamin Damilano, Hassen

Souissi, Christelle Brimont, Laetitia Doyennette, Thierry Guillet, Xavier Checoury, Moustafa El Kurdi, Sébastien Chenot, et al.

\section{To cite this version:}

Farsane Tabataba-Vakili, Blandine Alloing, Benjamin Damilano, Hassen Souissi, Christelle Brimont, et al.. Monolithic integration of ultraviolet microdisk lasers into photonic circuits in a III-nitride-onsilicon platform. Optics Letters, 2020, 45 (15), pp.4276-4279. 10.1364/OL.395371 . hal-02908380

\section{HAL Id: hal-02908380 \\ https://hal.science/hal-02908380}

Submitted on 28 Jul 2020

HAL is a multi-disciplinary open access archive for the deposit and dissemination of scientific research documents, whether they are published or not. The documents may come from teaching and research institutions in France or abroad, or from public or private research centers.
L'archive ouverte pluridisciplinaire HAL, est destinée au dépôt et à la diffusion de documents scientifiques de niveau recherche, publiés ou non, émanant des établissements d'enseignement et de recherche français ou étrangers, des laboratoires publics ou privés. 


\title{
Monolithic integration of ultraviolet microdisk lasers into photonic circuits in a III-nitride-on-silicon platform
}

\author{
Farsane Tabataba-Vakili ${ }^{1,2}$, Blandine Alloing ${ }^{3}$, Benjamin Damilano ${ }^{3}$, Hassen Souissi $^{4}$,

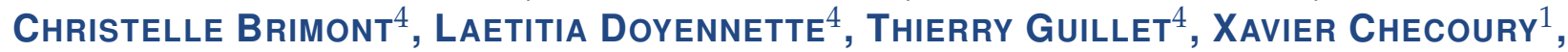 \\ Moustafa El Kurdi ${ }^{1}$, Sébastien Chenot ${ }^{3}$, Eric Frayssinet ${ }^{3}$, Jean-Yves Duboz ${ }^{3}$, Fabrice \\ Semond ${ }^{3}$, Bruno Gayral ${ }^{2}$, ANd Philippe Boucaud ${ }^{3,}{ }^{*}$ \\ ${ }^{1}$ Université Paris-Saclay, CNRS, C2N, 91120, Palaiseau, France. \\ ${ }^{2}$ Univ. Grenoble Alpes, CEA, IRIG-Pheliqs, 38000 Grenoble, France. \\ ${ }^{3}$ Université Côte d'Azur, CNRS, CRHEA, 06560 Valbonne, France. \\ ${ }^{4}$ L2C, Université de Montpellier, CNRS, 34095 Montpellier, France. \\ *Corresponding author: Philippe.Boucaud@crhea.cnrs.fr
}

Compiled July 28, 2020

Ultraviolet microdisk lasers are integrated monolithically into photonic circuits using a III-nitride on silicon platform with gallium nitride $(\mathrm{GaN})$ as the main waveguiding layer. The photonic circuits consist of a microdisk and a pulley waveguide terminated by outcoupling gratings. We measure quality factors up to 3500 under continuous-wave excitation. Lasing is observed from $374 \mathrm{~nm}$ to $399 \mathrm{~nm}$ under pulsed excitation, achieving low threshold energies of $0.14 \mathrm{~mJ} / \mathrm{cm}^{2}$ per pulse (threshold peak powers of $35 \mathrm{~kW} / \mathrm{cm}^{2}$ ). A large peak to background dynamic of around 200 is observed at the out-coupling grating for small gaps of $50 \mathrm{~nm}$ between the disk and waveguide. These devices operate at the limit of what can be achieved with $\mathrm{GaN}$ in terms of operation wavelength. (๑) 2020 Optical Society of America

\section{http://dx.doi.org/10.1364/ao.XX.XXXXXX}

In recent years, there has been a significant interest in ultraviolet (UV) emitters, such as light emitting diodes (LEDs) and optically pumped lasers for a variety of applications including germicidal sterilization and gas sensing [1,2]. The material system of choice for active devices in the UV spectrum is III-nitride, due to its band gap tunability from the UV-C to the visible spectrum.

III-nitride microcavity photonics is a very active field of research [3]. Individual microlasers in the UV spectral range have been realized under pulsed optical pumping [4-6] and electrical injection [7]. Photonic circuits in the UV have also recently gained popularity with potential applications including atomic clocks or precision metrology [8]. Several passive circuits have been demonstrated using aluminum nitride (AIN) [9-12] or aluminum oxide $\left(\mathrm{Al}_{2} \mathrm{O}_{3}\right)$ [13]. A simple active circuit using aluminum gallium nitride $(\mathrm{AlGaN})$ LEDs has also recently been demonstrated [14]. However, no demonstrations of active photonic circuits containing microlasers in the UV have been reported, while this would constitute an important step for the development of next generation photonic circuits.

Meanwhile, there have been several reports of optically pumped active microlaser photonic circuits in the blue using IIInitrides [15-17], as well as efforts to combine microrings under electrical injection with photonic circuits [18].

In this Letter, we report on the demonstration of active microlaser photonic circuits in the UV consisting of a microdisk, a pulley waveguide, and out-coupling gratings terminating the waveguide.

The investigated sample was grown by metal organic chemical vapor deposition (MOCVD) on silicon (111). First, a 220 $\mathrm{nm}$ AlN buffer layer was grown, followed by $300 \mathrm{~nm}$ of $\mathrm{GaN}$. Then the active region containing 5 pairs of $2 \mathrm{~nm} \mathrm{In}_{x} \mathrm{Ga}_{1-x} \mathrm{~N} / 9$ $\mathrm{nm}$ GaN quantum wells (QWs) (nominal indium composition $x=0.1$ ) was grown, followed by a $20 \mathrm{~nm}$ GaN cap layer. The total thickness is around $600 \mathrm{~nm}$.

We fabricated microdisk photonic circuits using a process similar to the one described in Refs. $[15,16]$. An $\mathrm{SiO}_{2}$ hard mask, e-beam lithography using UV5 resist, and inductively coupled plasma (ICP) etching with $\mathrm{CH}_{2} \mathrm{~F}_{2}$ and $\mathrm{CF}_{4}$ gases for the $\mathrm{SiO}_{2}$ and $\mathrm{Cl}_{2}$ and $\mathrm{BCl}_{3}$ gases for the III-nitrides were employed. The process consisted of two levels of lithography and etching. First, the microdisk, waveguide and grating couplers were defined, using proximity effect correction at the gap and a higher e-beam dose for the grating coupler. After the ICP etch, we performed a chemical treatment with AZ400K developer at $40^{\circ} \mathrm{C}$ to smooth the side-walls. In the second level, we opened an area containing the waveguide to etch away the QWs in order to avoid re-absorption of the emission. Finally, the silicon was underetched using $\mathrm{XeF}_{2}$ gas to provide for vertical confinement by refractive index contrast to air. We fabricated devices with $3 \mu \mathrm{m}$ diameter disks and waveguides with an angle of $180^{\circ}$ around the disk with nominally $125 \mathrm{~nm}$ width in the proximity of the disk and $500 \mathrm{~nm}$ width away from the disk. The distance from the center of the microdisk to the end of the waveguide is $50 \mu \mathrm{m}$. The grating couplers have a period of $200 \mathrm{~nm}$. The 
gap between the disk and the waveguide is varied between 40 and $100 \mathrm{~nm}$. These devices are particularly challenging to fabricate due to the fairly long suspension length of the waveguide with the $180^{\circ}$ bend. For larger microdisks we observe cracking of the nanotethers that hold the waveguide, which then falls. For suspension lengths smaller than $12 \mu \mathrm{m}$ the devices are stable. Thus, our devices are at the fabrication limit of suspended photonic circuits in this platform. The reason for using a $180^{\circ}$ waveguide bend is the increase in coupling length that allows to have efficient coupling at larger gaps. Using finite-difference time-domain (FDTD) simulations we estimate that the critical coupling gap is $20 \mathrm{~nm}$ larger than for a $90^{\circ}$ angle $(60 \mathrm{~nm}$ instead of $40 \mathrm{~nm}$ ) corresponding to the maximum coupling.

Fig. 1 (a) shows an optical microscope image of a fabricated device, clearly showing the underetched areas as well as the waveguide etch through color-contrast. Fig. 1 (b) shows a scanning electron microscope (SEM) image of a device, also indicating the underetch and clearly showing the nanotethers that hold the waveguide. Zoom-ins of the microdisk, the gap and the grating coupler are shown in Figs. 1 (c)-(e). In Fig. 1 (d) we can see the roughness of our very thin waveguides (nominally $125 \mathrm{~nm}$ ), which is visible due to the large zoom.

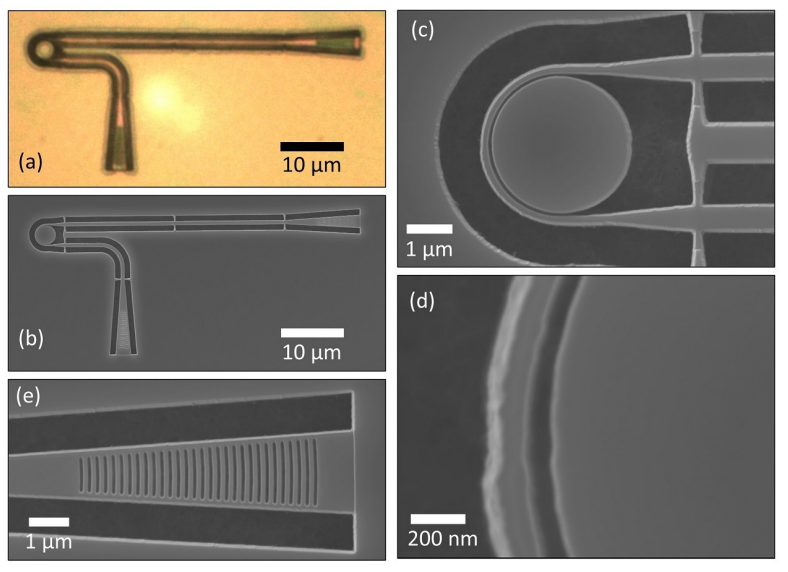

Fig. 1. (a) Optical microscope image and (b) SEM image of a photonic circuit. Zoom-ins of (c) the microdisk, (d) the coupling region, and (e) the grating coupler.

We employ a standard $\mu$-photoluminescence ( $\mu$-PL) setup with a continuous-wave (CW) laser emitting at $355 \mathrm{~nm}$ and a 20x microscope objective that is used to pump the device and to collect the emission that is then measured by a spectrometer and a charge-coupled device (CCD). A map of the CCD allows to differentiate between the emission from the disk and from the grating by integrating over different areas. We pump the microdisks at room temperature (RT) in order to determine the loaded $Q$ factors of our devices. The bottom part of Fig. 2 shows a CW spectrum measured from the top at the out-coupling grating for a device with $100 \mathrm{~nm}$ gap. Many modes are visible and their identification is difficult. We observe first-order modes with an FSR of $4 \mathrm{~nm}$ at $407.7 \mathrm{~nm}, 411.8 \mathrm{~nm}$, and $415.4 \mathrm{~nm}$ with $Q_{\text {load }}$ in the range of 1400 to 1800 , which are limited by QW absorption. The maximum $Q_{\text {load }}$ for the $100 \mathrm{~nm}$ gap is 3500 at $419.7 \mathrm{~nm}$ (potentially the next first-order mode), which is shown in the inset in Fig. 2. We note that under low power density CW excitation the QW emission is centered at around $407 \mathrm{~nm}$. The modes are not or barely visible above the microdisk under $\mathrm{CW}$ excitation in our top-collection setup, as whispering gallery modes (WGMs) radiate preferentially in-plane. Based on the $Q_{\text {load }}$ of the $100 \mathrm{~nm}$ gap device, we assume that the intrinsic $\mathrm{Q}$ factor $Q_{\text {int }}$ is 3500, which is in the same order of magnitude as for our previously investigated microdisks [5, 16, 19]. The $Q_{\text {load }}$ at $380 \mathrm{~nm}$ will certainly be lower due to the GaN absorption. $Q_{\text {int }}$ might be limited by side-wall roughness or surface absorption [20].

We can estimate the effective propagation losses of the microdisk using [21]

$$
\alpha_{\text {disk }}=\frac{\lambda_{0}}{Q_{\text {int }} \cdot F S R \cdot r}
$$

with $\lambda_{0}$ the resonance wavelength, FSR the free spectral range, and $r$ the radius of the disk. We obtain $\alpha=0.08 \mathrm{~dB} / \mu \mathrm{m}$ when extrapolating at $\lambda_{0}=380 \mathrm{~nm}, F S R=4 \mathrm{~nm}, Q_{\text {int }}=3500$, and $r=1.5 \mu \mathrm{m}$, which is two orders of magnitude larger than reported by Liu et al. for AlN microrings at $390 \mathrm{~nm}$ [12] and in the same order of magnitude as reported by Stegmaier et al. for polycrystaline AlN waveguides at $400 \mathrm{~nm}$ [9]. When comparing with Ref. [12], we need to consider several factors. Firstly, the different waveguiding material, GaN vs. AlN: GaN will have higher losses due to larger material absorption at $380 \mathrm{~nm}$, an absorption of $100 \mathrm{~cm}^{-1}$ would result in a $Q_{a b s}$ of 4200 . Secondly, the much higher radiation loss due to strong bending of a small microdisk $(r=1.5 \mu \mathrm{m})$ as compared to a large microring $(r=30 \mu \mathrm{m})$ [22]. Thirdly, the different refractive index contrasts between waveguide and cladding (air vs. $\mathrm{SiO}_{2} / \mathrm{Al}_{2} \mathrm{O}_{3}$ ): a smaller index contrast results in significantly lower scattering loss due to roughness. Lastly, the growth substrate, Si vs sapphire: a smaller dislocation density, which can be more easily achieved on sapphire, can induce lower internal losses. Furthermore, we employ much smaller gaps between the resonator and the waveguide than Liu et al., which renders our process more complex, but leads to better cavity to waveguide coupling.

In analogy to Ref. [12], we calculate $H_{z, s}^{2} /\left(\int H_{z}^{2} \mathrm{dxdz}\right)$, where $H_{z, s}$ is the the maximum field at the side-wall of the disk and the integral is taken over the $x-z$ cross-section, where $\mathrm{z}$ is the out-of-plane direction, using FDTD. For our microdisk, we obtain $2.3 \mu \mathrm{m}^{-2}$, which is an order of magnitude larger than the value obtained by Liu et al. for wide microrings [12]. The higher field at the interface can be explained by the larger curvature of a small disk compared to a large ring and results in larger side-wall losses, explaining in part the lower $Q$ factor we observe.

Lasing is observed at RT under pulsed optical conditions using a laser at $355 \mathrm{~nm}$ with $7 \mathrm{kHz}$ repetition rate and $4 \mathrm{~ns}$ pulse width. Fig. 2 shows pulsed spectra at peak powers of $34 \mathrm{~kW} / \mathrm{cm}^{2}\left(0.9 E_{t h}\right)$ and $101 \mathrm{~kW} / \mathrm{cm}^{2}\left(2.7 E_{t h}\right)$ measured at the out-coupling grating for a device with $100 \mathrm{~nm}$ gap. A strong blue-shift of around $25 \mathrm{~nm}$ is observed with increasing excitation power as we go from CW to pulsed excitation far above threshold. The blue-shift can be explained both by quantum confined Stark effect screening at large carrier density and by state-filling of localized states of the InGaN QWs. A smaller blue-shift was observed in our previous samples, as they were grown by molecular beam epitaxy (MBE) where less localization is observed [16]. Furthermore, it is very likely that excited states in the QWs are lasing. Considering the e1 (electron ground state) to hh1 (heavy hole ground state) transition at $3.05 \mathrm{eV}$ or $407 \mathrm{~nm}$, the center emission wavelength under low excitation CW pumping, an Indium composition of $13.5 \%$ in the QWs is deduced from 6 band k.p simulations without considering carrier interactions. This transition has an oscillator strength of 0.34 . The QWs are 


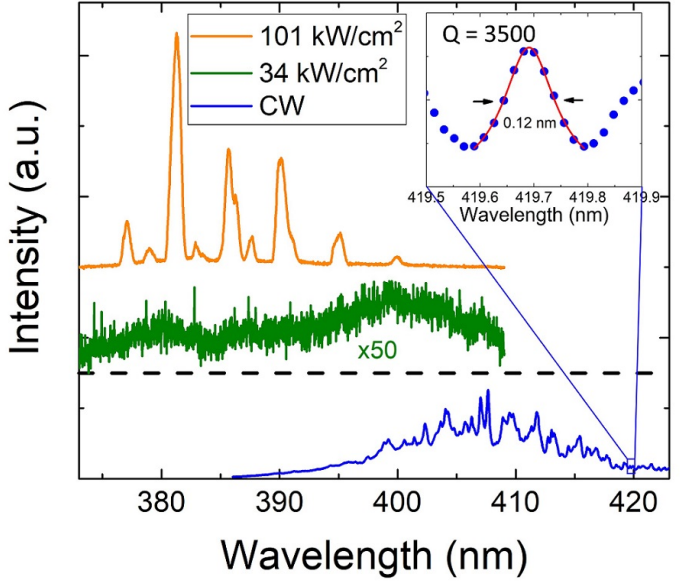

Fig. 2. Spectra below and above threshold taken at the outcoupling grating for devices with $100 \mathrm{~nm}$ gap. Bottom: Lowexcitation power density CW spectrum below threshold. The inset shows the maximum $Q$ factor of 3500 at the low energy side of the spectrum at $419.7 \mathrm{~nm}$. Top: Pulsed spectra below and above threshold. The spectra are displaced along the $y-$ axis and the CW spectrum has a different y-scale.

very asymmetric, which makes the cross-transitions (e2-hh1 and e1-hh2, where 2 denotes the first excited state) very intense. The oscillator strength of the e2-hh1 transition at $3.31 \mathrm{eV}$ or $375 \mathrm{~nm}$ is 0.23 . For the e1-hh2 transition at $3.13 \mathrm{eV}$ or $396 \mathrm{~nm}$ we get an oscillator strength of 0.12 . The emission thus encompasses the entire lasing spectral range of our devices.

The lasing modes are rather broad. The mode at $381.2 \mathrm{~nm}$ at $2.7 E_{t h}$ has a full-width at half maximum (FWHM) of $1 \mathrm{~nm}$. Generally under pulsed pumping, linewidths are broader than under CW pumping since the carrier density changes strongly in the microlaser during one pulse (here $4 \mathrm{~ns}$ ). We do not observe linewidth narrowing near the threshold, since the modes are not visible below threshold due to the limited signal to noise ratio under these low duty-cycle conditions.

Figs. 3 (a) and (c) show pulse energy dependent spectra measured above the microdisk for devices with $50 \mathrm{~nm}$ and 90 nm gaps, respectively. Spectra measured on the same devices but at the out-coupling grating are depicted in Figs. 3 (b) and (d). Lasing modes are observed from $374 \mathrm{~nm}$ to $399 \mathrm{~nm}$. The lowest threshold energy of $0.14 \mathrm{~mJ} / \mathrm{cm}^{2}$ per pulse or threshold peak power of $35 \mathrm{~kW} / \mathrm{cm}^{2}$ is observed for the $80 \mathrm{~nm}$ gap (not shown). The calculated overlap of the vertical $\mathrm{TE}_{0}$ mode with the QWs (excluding the barriers) is $1.0 \%$. This value could be increased by using cladding layers, but those would result in a much thicker structure that makes suspended photonic circuits more difficult to fabricate.

The first-order radial WGMs are visible for both $50 \mathrm{~nm}$ and 90 nm gaps (Fig. 3) with a spacing of 3.6 to $4.6 \mathrm{~nm}$ and azimuthal mode orders of $m=60$ at $374 \mathrm{~nm}$ to $m=54$ at $399 \mathrm{~nm}$, as determined by FDTD simulations. First one and then several first order modes lase, followed by other modes of higher order, which are especially visible at high energy for the larger gaps (Figs. 2 and $3(\mathrm{c}, \mathrm{d})$ ). We observe a very large dynamic of the peak to background emission of around 200 at $3 E_{t h}$ for the $50 \mathrm{~nm}$ gap device at the grating coupler, with only a factor 10 observed directly at the disk. The improvement of this dynamic with increased coupling is due to the fact that the WGMs radiate
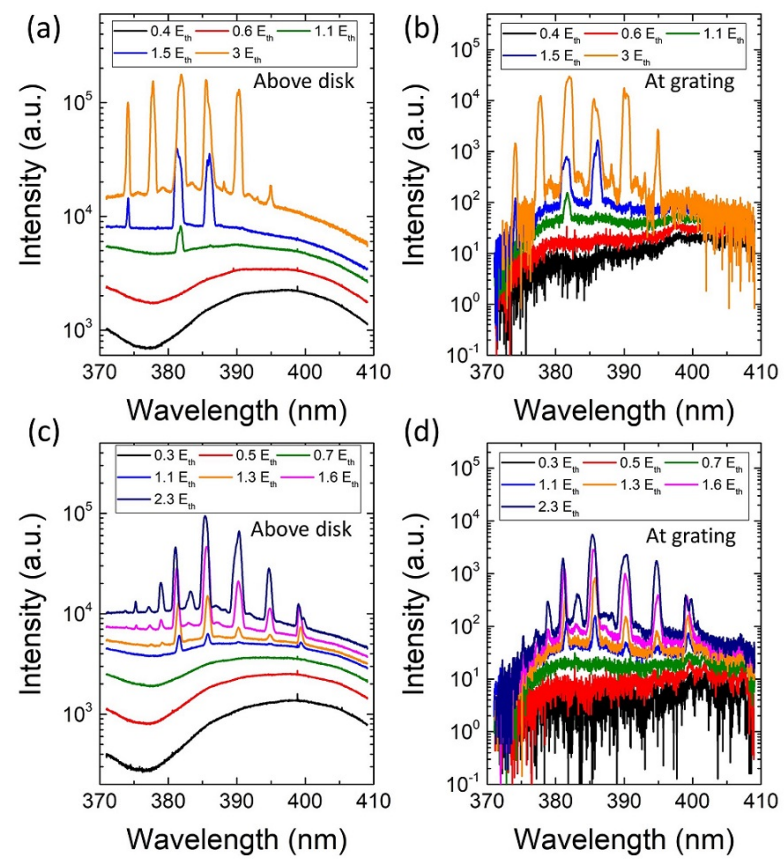

Fig. 3. Energy dependent pulsed optical pumping spectra of measured $(\mathrm{a}, \mathrm{c})$ above the disk and $(\mathrm{c}, \mathrm{d})$ at the grating coupler for devices with $(\mathrm{a}, \mathrm{b})$ a $50 \mathrm{~nm}$ gap and $(\mathrm{c}, \mathrm{d})$ an $90 \mathrm{~nm}$ gap. The thresholds are $0.18 \mathrm{~mJ} / \mathrm{cm}^{2}$ per pulse for the $50 \mathrm{~nm}$ gap and $0.15 \mathrm{~mJ} / \mathrm{cm}^{2}$ per pulse for the $90 \mathrm{~nm}$ gap.

preferentially in-plane, while the spontaneous QW emission radiates mainly out-of-plane. In FDTD transmission simulations we obtain a maximum coupling of $70 \%$ for a gap of $60 \mathrm{~nm}$.

The threshold peak powers, reported here, for pulsed IIInitride microdisk lasers are lower than what we have found in literature. Simeonov et al. reported $166 \mathrm{~kW} / \mathrm{cm}^{2}$ at $409 \mathrm{~nm}$ [23] and Zhu et al. $180 \mathrm{~kW} / \mathrm{cm}^{2}$ at $380 \mathrm{~nm} \mathrm{[6].} \mathrm{We} \mathrm{reported}$ lasing thresholds of $300 \mathrm{~kW} / \mathrm{cm}^{2}$ for microdisk photonic circuits operating at $420 \mathrm{~nm}$ [16]. The threshold reduction of one order of magnitude for our samples is primarily due to a change in growth method from MBE to MOCVD for our QWs. MBE grown QWs have a lower radiative efficiency due to a higher concentration of point defects caused by the lower growth temperature [24]. We can compare our thresholds to pulsed electrically injected lasing reported by Wang et al. with a threshold current density of $250 \mathrm{kA} / \mathrm{cm}^{2}$ (or at least $800 \mathrm{~kW} / \mathrm{cm}^{2}$ assuming operation at at least $3.2 \mathrm{~V}$ ) at $386 \mathrm{~nm}$ [7] for a $6.5 \mu \mathrm{m}$ thick heterostructure.

It is important to take into account that we are very close to the band gap of $\mathrm{GaN}$ (365 nm) in this spectral range (374 $399 \mathrm{~nm}$ ). Our waveguides consist to $58 \%$ of $\mathrm{GaN}$ and to $42 \%$ of AlN with $99 \%$ of the $\mathrm{TE}_{0}$ and $94 \%$ of the $\mathrm{TE}_{1}$ modes confined in the GaN layer. Consequently, there is a non-zero absorption loss that needs to be considered. The precise value of below band gap GaN absorption varies from one growth reactor to another but could be in the range of $1000 \mathrm{~cm}^{-1}$ at $380 \mathrm{~nm}$ [25]. We are thus at the absolute wavelength limit of what can be achieved with a GaN waveguide. In order to decend further in wavelength, we would need to use a waveguide consisting only or mostly of AlN to reduce the absorption loss. Furthermore, using $\mathrm{Al}_{x} \mathrm{Ga}_{1-x} \mathrm{~N} / \mathrm{Al}_{y} \mathrm{Ga}_{1-y} \mathrm{~N}(y>x)$ instead of InGaN/GaN 
QWs would allow to reduce the emission wavelength into the UV-B and UV-C. Such photonic circuits are feasible, but remain very difficult to implement due to a need for even smaller gaps for efficient coupling as well as difficulties in growing high quality material.
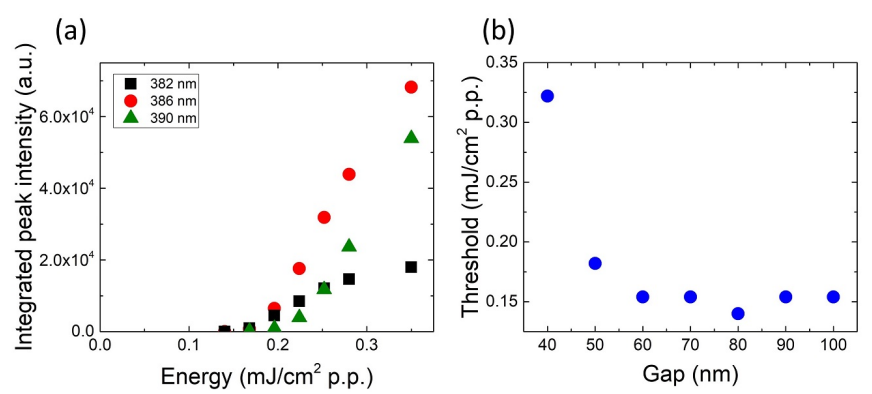

Fig. 4. (a) Integrated peak intensity over pulse energy for the modes at 382, 386, and $390 \mathrm{~nm}$ for the device with $90 \mathrm{~nm}$ gap shown in Fig. 3 (c,d) and (b) Threshold energy over nominal gap size.

In Fig. 4 (a) we show the integrated peak intensity over the energy per pulse for the modes at 382,386, and $390 \mathrm{~nm}$, for the device with $90 \mathrm{~nm}$ gap (Figs. 3 (c,d)). The lasing thresholds at $E=0.15$ and $0.19 \mathrm{~mJ} / \mathrm{cm}^{2}$ per pulse are clearly visible. The threshold energy as a function of nominal gap size is shown in Fig. 4 (b). We can see that the threshold decreases with increasing gap, which is to be expected, since $E_{t h} \propto 1 / Q_{\text {load }}$ and since $Q_{\text {load }}$ decreases with increased coupling [16]. For the 40 nm gap, the threshold is particularly high because the gap is not fully open, since these distances are at the limit of what can be achieved using e-beam lithography with UV5 resist.

In conclusion, we have demonstrated active microlaser photonic circuits in the UV-A spectral range using the III-nitride on silicon platform, which is very promising for both active and passive photonic components for next generation photonic integration. Our devices operate at the limit of what can be achieved using GaN as the waveguiding layer. The wavelength can be further reduced by switching from InGaN/GaN to $\mathrm{Al}_{x} \mathrm{Ga}_{1-x} \mathrm{~N} / \mathrm{Al}_{y} \mathrm{Ga}_{1-y} \mathrm{~N}(y>x)$ QWs and the absorption losses can be reduced by using AlN instead of GaN/AlN for the waveguide. Possible applications of such devices could be for gas sensing [26].

We thank Damir Vodenicarevic for his help with python scripts for data analysis. We also thank Sébastien Sauvage for fruitful discussions. This work was supported by the French Agence Nationale de la Recherche (ANR) under MILAGAN convention (ANR-17-CE08-0043-02). We acknowledge support by a public grant overseen by the ANR as part of the "Investissements d'Avenir" program: Labex GANEX (Grant No. ANR-11-LABX0014). This work was also partly supported by the RENATECH network. We acknowledge the support from the technical teams at PTA-Grenoble, Nanofab (Institut Néel) and CRHEA.

Disclosures. The authors declare no conflicts of interest.

\section{REFERENCES}

1. S. Nakamura, Science 281, 956 (1998).

2. M. Kneissl and J. Rass, III-Nitride Ultraviolet Emitters (Springer Science \& Business Media, 2016).
3. R. Butté and N. Grandjean, Nanophotonics 9, 569 (2020).

4. J. Sellés, C. Brimont, G. Cassabois, P. Valvin, T. Guillet, I. Roland, Y. Zeng, X. Checoury, P. Boucaud, M. Mexis, F. Semond, and B. Gayral, Sci. Reports 6, 21650 (2016).

5. J. Sellés, V. Crepel, I. Roland, M. E. Kurdi, X. Checoury, P. Boucaud, M. Mexis, M. Leroux, B. Damilano, S. Rennesson, F. Semond, B. Gayral, C. Brimont, and T. Guillet, Appl. Phys. Lett. 109, 231101 (2016).

6. G. Zhu, J. Li, N. Zhang, X. Li, J. Dai, Q. Cui, Q. Song, C. Xu, and Y. Wang, Sci. Reports 10, 1 (2020).

7. J. Wang, M. Feng, R. Zhou, Q. Sun, J. Liu, Y. Huang, Y. Zhou, H. Gao, X. Zheng, M. Ikeda, and H. Yang, Photonics Res. 7, B32 (2019).

8. D. J. Blumenthal, APL Photonics 5, 020903 (2020).

9. M. Stegmaier, J. Ebert, J. M. Meckbach, K. llin, M. Siegel, and W. H. P. Pernice, Appl. Phys. Lett. 104, 091108 (2014).

10. M. Soltani, R. Soref, T. Palacios, and D. Englund, Opt. Express 24, 25415 (2016).

11. T.-J. Lu, M. Fanto, H. Choi, P. Thomas, J. Steidle, S. Mouradian, W. Kong, D. Zhu, H. Moon, K. Berggren, J. Kim, M. Soltani, S. Preble, and D. Englund, Opt. Express 26, 11147 (2018).

12. X. Liu, A. W. Bruch, Z. Gong, J. Lu, J. B. Surya, L. Zhang, J. Wang, J. Yan, and H. X. Tang, Optica 5, 1279 (2018).

13. G. N. West, W. Loh, D. Kharas, C. Sorace-Agaskar, K. K. Mehta, J. Sage, J. Chiaverini, and R. J. Ram, APL Photonics 4, 026101 (2019).

14. R. Floyd, K. Hussain, A. Mamun, M. Gaevski, G. Simin, M. Chandrashekhar, and A. Khan, Appl. Phys. Express 13, 022003 (2020).

15. F. Tabataba-Vakili, L. Doyennette, C. Brimont, T. Guillet, S. Rennesson, E. Frayssinet, B. Damilano, J.-Y. Duboz, F. Semond, I. Roland, M. El Kurdi, X. Checoury, S. Sauvage, B. Gayral, and P. Boucaud, ACS Photonics 5, 3643 (2018).

16. F. Tabataba-Vakili, L. Doyennette, C. Brimont, T. Guillet, S. Rennesson, B. Damilano, E. Frayssinet, J.-Y. Duboz, X. Checoury, S. Sauvage, M. El Kurdi, F. Semond, B. Gayral, and P. Boucaud, Sci Rep 9, 18095 (2019).

17. C. H. To, W. Y. Fu, K. H. Li, Y. Cheung, and H. Choi, Opt. Lett. 45, 791 (2020).

18. F. Tabataba-Vakili, S. Rennesson, B. Damilano, E. Frayssinet, J.-Y. Duboz, F. Semond, I. Roland, B. Paulillo, R. Colombelli, M. El Kurdi, X. Checoury, S. Sauvage, L. Doyennette, C. Brimont, T. Guillet, B. Gayral, and P. Boucaud, Opt. Express 27, 11800 (2019).

19. M. Mexis, S. Sergent, T. Guillet, C. Brimont, T. Bretagnon, B. Gil, F. Semond, M. Leroux, D. Néel, S. David, X. Checoury, and P. Boucaud, Opt. Lett. 36, 2203 (2011).

20. I. Rousseau, G. Callsen, G. Jacopin, J.-F. Carlin, R. Butté, and N. Grandjean, J. Appl. Phys. 123, 113103 (2018).

21. L.-W. Luo, G. S. Wiederhecker, J. Cardenas, C. Poitras, and M. Lipson, Opt. Express 19, 6284 (2011).

22. H. A. Haus, M. A. Popović, M. R. Watts, C. Manolatou, B. E. Little, and S. T. Chu, "Optical resonators and filters," in Optical microcavities, (World Scientific, 2004), pp. 1-37.

23. D. Simeonov, E. Feltin, A. Altoukhov, A. Castiglia, J.-F. Carlin, R. Butté, and N. Grandjean, Appl. Phys. Lett. 92, 171102 (2008).

24. E. Young, N. Grandjean, T. Mates, and J. Speck, Appl. Phys. Lett. 109, 212103 (2016).

25. G. Yu, G. Wang, H. Ishikawa, M. Umeno, T. Soga, T. Egawa, J. Watanabe, and T. Jimbo, Appl. Phys. Lett. 70, 3209 (1997).

26. M.-C. Estevez, M. Alvarez, and L. M. Lechuga, Laser Photonics Rev. 6, 463 (2012). 


\section{FULL REFERENCES}

1. S. Nakamura, "The roles of structural imperfections in InGaN-based blue light-emitting diodes and laser diodes," Science. 281, 956-961 (1998).

2. M. Kneissl and J. Rass, III-Nitride Ultraviolet Emitters (Springer Science \& Business Media, 2016).

3. R. Butté and N. Grandjean, "III-nitride photonic cavities," Nanophotonics. 9, 569-598 (2020).

4. J. Sellés, C. Brimont, G. Cassabois, P. Valvin, T. Guillet, I. Roland, Y. Zeng, X. Checoury, P. Boucaud, M. Mexis, F. Semond, and B. Gayral, "Deep-UV nitride-on-silicon microdisk lasers," Sci. Reports 6, 21650 (2016).

5. J. Sellés, V. Crepel, I. Roland, M. E. Kurdi, X. Checoury, P. Boucaud, M. Mexis, M. Leroux, B. Damilano, S. Rennesson, F. Semond, B. Gayral, C. Brimont, and T. Guillet, "lii-nitride-on-silicon microdisk lasers from the blue to the deep ultra-violet," Appl. Phys. Lett. 109, 231101 (2016).

6. G. Zhu, J. Li, N. Zhang, X. Li, J. Dai, Q. Cui, Q. Song, C. Xu, and $Y$. Wang, "Whispering-gallery mode lasing in a floating GaN microdisk with a vertical slit," Sci. Reports 10, 1-7 (2020).

7. J. Wang, M. Feng, R. Zhou, Q. Sun, J. Liu, Y. Huang, Y. Zhou, H. Gao, $X$. Zheng, M. Ikeda, and H. Yang, "GaN-based ultraviolet microdisk laser diode grown on Si," Photonics Res. 7, B32-B35 (2019).

8. D. J. Blumenthal, "Photonic integration for UV to IR applications," APL Photonics 5, 020903 (2020).

9. M. Stegmaier, J. Ebert, J. M. Meckbach, K. llin, M. Siegel, and W. H. P. Pernice, "Aluminum nitride nanophotonic circuits operating at ultraviolet wavelengths," Appl. Phys. Lett. 104, 091108 (2014).

10. M. Soltani, R. Soref, T. Palacios, and D. Englund, "AIGaN/AIN integrated photonics platform for the ultraviolet and visible spectral range," Opt. Express 24, 25415 (2016).

11. T.-J. Lu, M. Fanto, H. Choi, P. Thomas, J. Steidle, S. Mouradian, W. Kong, D. Zhu, H. Moon, K. Berggren, J. Kim, M. Soltani, S. Preble, and D. Englund, "Aluminum nitride integrated photonics platform for the ultraviolet to visible spectrum," Opt. Express 26, 11147-11160 (2018).

12. X. Liu, A. W. Bruch, Z. Gong, J. Lu, J. B. Surya, L. Zhang, J. Wang, J. Yan, and H. X. Tang, "Ultra-high-Q UV microring resonators based on single-crystalline AIN platform," Optica 5, 1279-1282 (2018).

13. G. N. West, W. Loh, D. Kharas, C. Sorace-Agaskar, K. K. Mehta, J. Sage, J. Chiaverini, and R. J. Ram, "Low-loss integrated photonics for the blue and ultraviolet regime," APL Photonics 4, 026101 (2019).

14. R. Floyd, K. Hussain, A. Mamun, M. Gaevski, G. Simin, M. Chandrashekhar, and $\mathrm{A}$. Khan, "Photonics integrated circuits using $\mathrm{Al}_{x} \mathrm{Ga}_{1-x} \mathrm{~N}$ based UVC light-emitting diodes, photodetectors and waveguides," Appl. Phys. Express 13, 022003 (2020).

15. F. Tabataba-Vakili, L. Doyennette, C. Brimont, T. Guillet, S. Rennesson, E. Frayssinet, B. Damilano, J.-Y. Duboz, F. Semond, I. Roland, M. El Kurdi, X. Checoury, S. Sauvage, B. Gayral, and P. Boucaud, "Blue microlasers integrated on a photonic platform on silicon," ACS Photonics 5, 3643-3648 (2018).

16. F. Tabataba-Vakili, L. Doyennette, C. Brimont, T. Guillet, S. Rennesson, B. Damilano, E. Frayssinet, J.-Y. Duboz, X. Checoury, S. Sauvage, M. El Kurdi, F. Semond, B. Gayral, and P. Boucaud, "Demonstration of critical coupling in an active III-nitride microdisk photonic circuit on silicon," Sci Rep 9, 18095 (2019).

17. C. H. To, W. Y. Fu, K. H. Li, Y. Cheung, and H. Choi, "GaN microdisk with direct coupled waveguide for unidirectional whispering gallery mode emission," Opt. Lett. 45, 791-794 (2020).

18. F. Tabataba-Vakili, S. Rennesson, B. Damilano, E. Frayssinet, J.-Y. Duboz, F. Semond, I. Roland, B. Paulillo, R. Colombelli, M. El Kurdi, X. Checoury, S. Sauvage, L. Doyennette, C. Brimont, T. Guillet, B. Gayral, and P. Boucaud, "III-nitride on silicon electrically injected microrings for nanophotonic circuits," Opt. Express 27, 11800-11808 (2019).

19. M. Mexis, S. Sergent, T. Guillet, C. Brimont, T. Bretagnon, B. Gil, F. Semond, M. Leroux, D. Néel, S. David, X. Checoury, and P. Boucaud, "High quality factor nitride-based optical cavities: microdisks with embedded GaN/AI(Ga)N quantum dots," Opt. Lett. 36, 2203-2205
(2011).

20. I. Rousseau, G. Callsen, G. Jacopin, J.-F. Carlin, R. Butté, and N. Grandjean, "Optical absorption and oxygen passivation of surface states in III-nitride photonic devices," J. Appl. Phys. 123, 113103 (2018).

21. L.-W. Luo, G. S. Wiederhecker, J. Cardenas, C. Poitras, and M. Lipson, "High quality factor etchless silicon photonic ring resonators," Opt. Express 19, 6284-6289 (2011).

22. H. A. Haus, M. A. Popović, M. R. Watts, C. Manolatou, B. E. Little, and S. T. Chu, "Optical resonators and filters," in Optical microcavities, (World Scientific, 2004), pp. 1-37.

23. D. Simeonov, E. Feltin, A. Altoukhov, A. Castiglia, J.-F. Carlin, R. Butté, and N. Grandjean, "High quality nitride based microdisks obtained via selective wet etching of AllnN sacrificial layers," Appl. Phys. Lett. 92, 171102 (2008).

24. E. Young, N. Grandjean, T. Mates, and J. Speck, "Calcium impurity as a source of non-radiative recombination in (In, Ga) N layers grown by molecular beam epitaxy," Appl. Phys. Lett. 109, 212103 (2016).

25. G. Yu, G. Wang, H. Ishikawa, M. Umeno, T. Soga, T. Egawa, J. Watanabe, and T. Jimbo, "Optical properties of wurtzite structure GaN on sapphire around fundamental absorption edge (0.78-4.77 eV) by spectroscopic ellipsometry and the optical transmission method," Appl. Phys. Lett. 70, 3209-3211 (1997)

26. M.-C. Estevez, M. Alvarez, and L. M. Lechuga, "Integrated optical devices for lab-on-a-chip biosensing applications," Laser Photonics Rev. 6, 463-487 (2012). 